\title{
Avaliando o Uso do Aplicativo "Embaralhado" no Processo de Alfabetização
}

Jeferson José da Silva - UFPB, jeferson.silva@dce.ufpb.br

Ayla Débora Dantas de Souza Rebouças - UFPB, ayla@dcx.ufpb.br

Resumo. A avaliação de objetos de aprendizagem (OA) que buscam apoiar o processo de alfabetização se faz mais que necessária no contexto tecnológico atual, pois atividades mais tradicionais como exercícios de repetição nem sempre conseguem manter a atenção dos alunos, o que gera desmotivação durante esse processo. Neste artigo é apresentado o "Embaralhado", um OA personalizável para a plataforma Android desenvolvido com o objetivo de auxiliar o processo de alfabetização de maneira lúdica. São apresentados dados relativos a uma avaliação por meio de observação direta de alunos inseridos no processo de alfabetização. Além disso, são apresentados resultados de uma avaliação que considerou o nível de satisfação e aceitabilidade do "Embaralhado" por parte de professores e pais/responsáveis. De maneira geral, pelas avaliações realizadas foi possível identificar no aplicativo aspectos técnicos positivos como: robustez, estabilidade, adaptabilidade de acordo com as necessidades de cada usuário e um uso adequado do emprego de imagens. Percebeu-se também que o "Embaralhado" foi bem aceito por pais/responsáveis e professores e que pode apoiar o processo de alfabetização favorecendo a motivação.

Palavras-chave: Alfabetização, objetos de aprendizagem, avaliação de softwares educacionais.

\section{Evaluating the Use of the "Embaralhado" Application in the Literacy Process}

Abstract. The evaluation of learning objects (LO) that seek to support the literacy process is more than necessary in the current technological context, since more traditional activities such as repetition exercises cannot always keep students' attention, which leads to demotivation during this process. In this article, we present "Embaralhado", which is a customizable LO for the Android platform that we have developed with the objective to help the literacy process in a playful way. We also present some results of an evaluation through direct observations of students inserted in the literacy process. In addition, we show the results of an evaluation that considered the level of satisfaction and acceptability of "Embaralhado" by teachers and parents/ guardians of children involved in the literacy process. In general, through the evaluations performed we could identify the following positive technical aspects: robustness, stability, adaptability according to the needs of each user and an adequate use of images. Another result was that the application was well accepted by parents/ guardians and teachers and that it can support the process of literacy favoring the motivation.

Keywords: Literacy, learning objects, evaluation of educational software.

\section{Introdução}

A educação passa por um período em que o uso de um conjunto de atividades com metodologias mais tradicionais de aprendizagem de ensino nem sempre é suficiente para as atuais gerações de alunos que já nascem imersos na tecnologia. Sendo assim, fica evidente a necessidade de fazer uma análise profunda de possíveis aplicativos que tragam inovação e evolução no processo de ensino-aprendizagem.

Atualmente, tanto na literatura quanto nas principais lojas de aplicativos voltadas para dispositivos móveis, existem alguns aplicativos e sistemas que propõem 
apoiar o processo de alfabetização visando tornar as atividades mais motivantes para o aluno. Em muitos ambientes são utilizados exercícios com repetições que não conseguem prender a atenção dos estudantes, como reforçam da Silva Netto e Santos (2012). Segundo Pérsio e Bertoso (2012), por vezes os materiais didáticos contêm exercícios que não condizem com a linguagem em que o aluno e a escola estão inseridos, o que dificulta também o seu uso já que é interessante uma contextualização com a realidade do aluno e com o que é trabalhado em sala de forma a gerar uma aprendizagem significativa.

O processo de ensinar a ler e escrever é uma fase de ampliação da aprendizagem e do conhecimento do educando, e consequentemente, do seu desenvolvimento neurológico. Oliveira (2017) afirma que o ato de alfabetizar não é um processo tão simples de ser desenvolvido. Isto ocorre porque existem diversos problemas que podem afetar o desempenho do aluno durante o processo de alfabetização. Um dos problemas que se pode citar é conseguir transformar esse processo em algo mais dinâmico fazendo com que a atenção dos alunos seja capturada durante os exercícios das aulas ou de casa. Sabe-se que nos dias atuais está cada vez mais difícil conseguir obter a atenção dos alunos com o uso de metodologias mais tradicionais nas aulas, como por exemplo, o uso de materiais estáticos e exercícios de repetição. Conforme afirmam Sales Alves et al. (2012), alunos têm características, interesses, capacidades e necessidades de aprendizagem que são únicos a cada indivíduo, o que acaba muitas vezes tornando difícil o sucesso no processo de alfabetização.

Segundo dados informados pela Pesquisa Nacional por Amostra de Domicílios (Pnad) de $2014^{1}$, realizada pelo Instituto Brasileiro de Geografia e Estatística (IBGE), há no Brasil uma taxa de analfabetismo estimada em $8,3 \%$, que é bastante preocupante principalmente na região nordeste do país, onde os índices de analfabetismo estão na faixa dos $16,6 \%$, a tornando a região com o maior número de analfabetos do Brasil.

Souza (2012) declara que "Softwares educacionais, quando destinados às crianças em idade de alfabetização, podem apresentar propostas inovadoras, influenciadas pelas contribuições das recentes pesquisas da psicologia e da linguística". Diante dessa afirmação, podemos concluir que jogos educativos podem ser poderosos aliados para que os alunos possam compreender o sistema de escrita. Brincando, desde que com boa orientação, os alunos podem compreender os princípios de funcionamento do sistema alfabético e podem socializar seus saberes com os colegas.

Diante desse contexto, este trabalho tem como objetivo apresentar o Objeto de Aprendizagem (OA) personalizável intitulado "Embaralhado" e sua avaliação, analisando a sua aceitabilidade. A aceitabilidade é analisada sob o ponto de vista dos professores que lecionem em séries iniciais e pais/responsáveis que acompanhem crianças em processo de alfabetização. A sua avaliação é feita analisando aspectos pedagógicos e técnicos com base nas observações dos pesquisadores deste trabalho, de acordo com as diretrizes para avaliação de objetos de aprendizagem propostas por Reategui e Finco (2010). Este OA possui a temática do embaralhamento das letras que constituem uma palavra relacionada a uma figura e o seu diferencial é que seu conteúdo é totalmente personalizável. Usuários têm a liberdade para criar novos desafios e personalizar todos os desafios do jogo da maneira que sentirem necessidade, o que vai contribuir para uma adequação aos seus contextos sociais e culturais ou mesmo ao que vêm trabalhando na escola. Esta é uma proposta que se diferencia das demais, visto que

\footnotetext{
${ }^{1} \mathrm{http}: / /$ portal.mec.gov.br/busca-geral/211-noticias/218175739/31991-pesquisa-aponta-reducao-no-indicede-analfabetismo-no-pais
} 
a maioria dos objetos de aprendizagem propostos para essa fase na educação em geral oferecem sempre o mesmo conteúdo e não permitem edição deste.

Considerando o que foi apresentado, as seções posteriores deste trabalho estão estruturadas da seguinte forma: na Seção 2 é apresentada a metodologia adotada, na Seção 3 é apresentado o referencial teórico, na Seção 4 é apresentada a descrição do aplicativo proposto por esse trabalho, na Seção 5 são apresentados trabalhos relacionados encontrados na literatura e na loja de aplicativos da Google Play Store voltados para a alfabetização, na Seção 6 será apresentada uma avaliação por observação direta segundo diretrizes propostas por Reategui e Finco (2010), na Seção 7 é apresentada a avaliação do OA por professores e pais e na Seção 8 serão apresentadas as conclusões e trabalhos futuros.

\section{Metodologia}

Este trabalho apresenta uma metodologia de pesquisa de caráter exploratório. Esta modalidade de pesquisa tem como objetivo proporcionar uma maior familiaridade com o problema, com o intuito de torná-lo mais explícito ou constituir hipóteses mais refinadas. Sendo assim, esta modalidade de pesquisa tem como objetivo principal o aprimoramento de ideias ou a descoberta de intuições, conforme destaca Gil (2002).

O trabalho iniciou-se através de uma revisão bibliográfica, com o propósito de conhecer melhor trabalhos relacionados ao uso das TICs para apoiar a alfabetização, bem como para preparação do referencial teórico sobre Objetos de Aprendizagem, Observação direta e técnicas para avaliá-los.

Em seguida, foi realizado um levantamento dos principais aplicativos educacionais na área da alfabetização tanto na literatura encontrada na revisão bibliográfica quanto em aplicativos que estão disponíveis na loja de aplicativos da Google Play Store. O objetivo deste levantamento foi identificar os pontos positivos e negativos de cada aplicativo, os relacionando e comparando com o OA avaliado neste trabalho. Sendo assim, foram selecionados 3 (três) softwares/aplicativos que tivessem maior relação com o "Embaralhado", com características como associação de palavras e figuras, o uso do Drag and Drop, ou a utilização de um banco de dados que seja customizável ou colaborativo. As chaves de busca para fazer esse levantamento foram: "Alfabetização", "Abc" e "Literacy".

O terceiro passo consistiu no processo de avaliar critérios pedagógicos, técnicos e nível de aceitação do "Embaralhado", analisando o seu uso dentro do processo de alfabetização. Para esta etapa, foi realizada uma avaliação por observação direta, analisando o comportamento de crianças matriculadas no Instituto Agras de Ensino, situado na cidade de Mamanguape-PB. Foram levados em consideração nesta avaliação critérios de avaliação de Objetos de Aprendizagem propostos por Reategui e Finco (2010). O objetivo foi de identificar através da observação direta qual é a abordagem pedagógica em que melhor se enquadra o "Embaralhado", quais as principais dificuldades de utilização e identificar quais eventuais erros e problemas poderiam acontecer durante a sua execução, além de observar questões técnicas que poderão ser melhoradas futuramente.

Por fim, para o processo de avaliação da aceitação do aplicativo segundo a perspectiva dos pais/responsáveis e professores que lecionem em séries iniciais, ou que trabalhem diretamente no processo de alfabetização, foram utilizados formulários online. Estes, por sua vez, são uma adaptação dos formulários utilizados por Oliveira (2017) em seu trabalho. Esperava-se que através deles fosse possível verificar o nível de 
aceitabilidade por parte dos usuários além de obter resultados objetivos que possam ajudar no processo de evolução e desenvolvimento do "Embaralhado".

\section{Referencial Teórico}

Segundo Tarouco (2016), os objetos de aprendizagem são recursos educacionais que são utilizados para apoiar o processo de aprendizagem. Podemos citar como exemplos as simulações, as calculadoras eletrônicas, as animações, os tutoriais, os textos, os sites www, os clips de áudio e vídeo, as ilustrações, os diagramas, os mapas, os jogos, entre outros. Segundo Blandino (2013), "os Objetos de Aprendizagem podem contribuir para tornar o processo educativo mais contextualizado, lúdico e interativo".

Para realizar avaliação de um OA, é possível encontrar na literatura vários métodos, metodologias e técnicas de avaliação, a exemplo de: Método de Reeves descrito por Campos (1989); Técnica de Mucchielli, descrita por Silva (1998) e a Avaliação de LORI, publicada por Nesbit et al. (2009). Para este trabalho, decidiu-se pela utilização das diretrizes propostas por Reategui e Finco (2010) por considerar diferentes aspectos e parecer mais útil para que futuros usuários e desenvolvedores do "Embaralhado" no sentido de melhor conhecer esse OA.

A avaliação descrita por Reategui e Finco (2010) consiste em um conjunto de questões dividido em duas seções: Aspectos Pedagógicos e Aspectos Técnicos. Nos aspectos pedagógicos as questões estão divididas em duas subseções relacionadas à perspectiva epistemológica e à capacidade de adaptação do OA analisado. $\mathrm{Na}$ perspectiva epistemológica, as questões têm o objetivo de poder identificar qual é a abordagem pedagógica na qual o $\mathrm{OA}$ mais se enquadra, mais precisamente, na abordagem Construtivista, Comportamentalista ou Sócio-Interacionista. Já na Capacidade de adaptação as questões têm o objetivo de analisar o quanto o OA está atento aos estilos identificados de aprendizagem e o quanto está adequado com respeito à apresentação do conteúdo proposto. Dando continuidade, esta proposta ainda busca analisar os aspectos Técnicos do OA analisando requisitos como: Robustez e Portabilidade, além de critérios relacionados à interface como: Emprego de imagens, Apresentação de informações, Orientação e navegação, Interatividade, Estética e Afetividade. A medida que o avaliador vai respondendo ao questionamento proposto, é possível identificar em qual abordagem pedagógica o OA mais se encaixa e também possíveis deficiências do ponto de vista técnico de forma a permitir a identificação de melhorias e a reflexão sobre os aspectos pedagógicos relativos ao uso do OA.

Para esta avaliação se utilizou a observação direta. Maffezzolli e Boehs (2008) explicam que visitar o local da pesquisa com o intuito de utilizar essa metodologia auxilia na compreensão do contexto e dos fenômenos estudados na pesquisa. No caso deste trabalho, buscou-se uma maior compreensão do uso do "Embaralhado" dentro do processo de alfabetização, considerando os critérios definidos por Reategui e Finco (2010).

\section{Descrição do aplicativo educacional "Embaralhado"}

O "Embaralhado" se trata de um objeto de aprendizagem (OA) na forma de um aplicativo para dispositivos móveis com a temática de um jogo que foi desenvolvido utilizando como ambiente de desenvolvimento o Android Studio 2.3.3 e a linguagem de programação Java. Atualmente está disponível na Google Play Store ${ }^{2}$ tanto para smartphones quanto para tablets que possuam como sistema operacional a plataforma Android a partir da versão 4.0.3, ou superior. O principal propósito desse jogo é auxiliar

\footnotetext{
${ }^{2}$ https://play.google.com/store/apps/details?id=com.mydroidtechnology.embaralhado
} 
o processo de alfabetização nas séries iniciais, podendo ser utilizado por parte dos professores na sala de aula com seus alunos, ou por parte dos pais/responsáveis em casa, para pessoas que estejam passando pelo processo de alfabetização.

O "Embaralhado" se baseia na ideia de apresentar de forma desorganizada as letras que constituem uma palavra que está associada a uma imagem e estas letras devem ser colocadas em ordem pelo usuário. Para isso, ele precisa clicar e arrastar as letras, de forma que ao final do desafio a palavra esteja corretamente escrita, conforme pode ser observado na Figura 1 usando como exemplo a palavra PATO. Se o jogador soltar a letra no espaço errado por engano, existe um botão para desfazer. Caso ocorra que o usuário posicione todas as letras nas suas respectivas posições corretamente e clique no botão de confirmação, um sinal sonoro de acerto será disparado e o jogo passará para o próximo desafio, se o mesmo existir. Em outro cenário, caso ocorra de uma ou mais letras não estarem na sua posição correta quando o jogador clicar no botão de confirmação, as letras posicionadas incorretamente serão retiradas e um sinal sonoro de erro será disparado, forçando o jogador a somente passar para o próximo desafio se o desafio que está sendo apresentado for concluído corretamente. Para jogar o usuário pode selecionar o contexto das palavras que deseja exercitar (e.g. animais, circo, etc). Além disso, alguém lhe auxiliando no processo de alfabetização pode configurar os contextos e palavras disponibilizados pelo jogo. O menu, a tela principal do aplicativo e a tela de seleção dos contextos que agrupam os desafios são ilustrados na Figura 1.

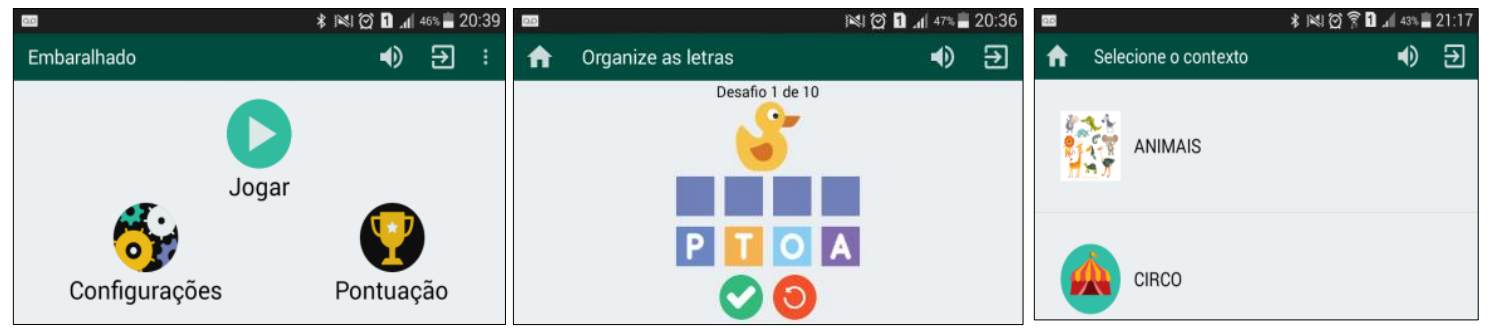

Figura 1. Menu, tela principal do jogo e tela de seleção de contexto

Para iniciar o jogo, o usuário clica no botão "Jogar" na tela inicial e deverá então selecionar um contexto de palavras e começar a partida. $\mathrm{O}$ jogador terá à disposição durante a partida um máximo de dez palavras por contexto selecionado.

O "Embaralhado" permite que usuários, especificamente pais/responsáveis ou professores, cadastrem em seus dispositivos novos contextos e desafios e imagens para representá-los. Isto é possível graças a um banco de dados local, ou seja, todos os cadastros de contextos e desafios que serão realizados estarão disponíveis apenas no dispositivo em que ocorrer essa operação. As imagens para fazer a associação com as palavras podem ser encontradas diretamente a partir da galeria de fotos ou da câmera do dispositivo onde o OA está instalado. Através do botão de "Configurações" os usuários podem fazer o gerenciamento de todos os contextos e desafios existentes, tanto dos que já vêm pré-instalados quanto dos novos contextos cadastrados pelos usuários. Isto permitirá personalizar todo o conteúdo do jogo, o moldando às necessidades de cada usuário. Outro ponto a ser esclarecido é o fato de que pais/responsáveis e professores poderão cadastrar quantas palavras acharem necessário. Estas funcionalidades de cadastro e gerenciamento de conteúdo (contextos e palavras) são ilustradas pela Figura 2. 


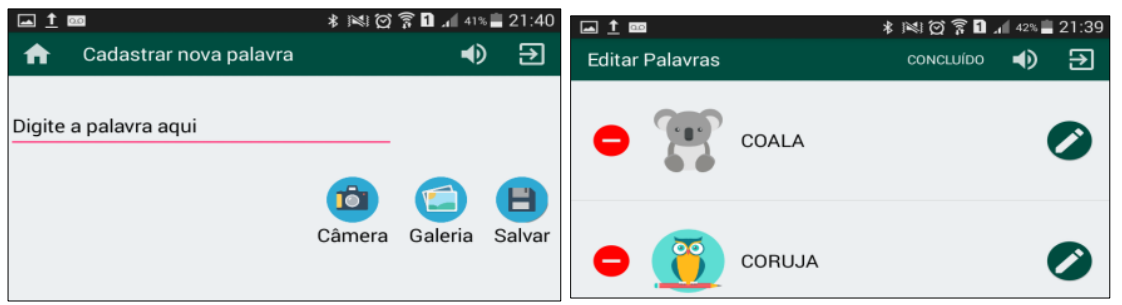

Figura 2. Telas de cadastro e edição de palavras

Uma vez que o usuário começa a jogar, os desafios de um certo contexto vão sendo mostrados em uma ordem aleatória. Dessa forma, sempre que o jogador voltar a jogar os desafios do mesmo contexto, espera-se que os desafios não sejam apresentados na mesma sequência e as letras que compõem cada desafio não estarão na mesma ordem. Ao final da partida, será requerido o nome do jogador e será apresentada uma tela com uma mensagem de parabéns onde o jogador receberá um troféu de acordo com a porcentagem de desafios acertados com apenas uma tentativa de verificação. Vale salientar que existem no jogo três tipos de troféus, sendo: um com três estrelas onde todos os desafios foram acertados, um troféu com duas estrelas para o jogador que acertou entre 50 e $70 \%$ dos desafios e um troféu com uma estrela para o jogador que acertou menos de $50 \%$ dos desafios com apenas uma tentativa de verificação cada. Por fim, no botão de "Pontuações" são exibidas as dez melhores pontuações de todos os jogadores, organizadas por contextos já jogados.

\section{Trabalhos Relacionados}

Esta seção apresenta os 3 aplicativos e softwares educacionais encontrados e selecionados na Google Play Store e na literatura que visam apoiar o processo de alfabetização mais relacionados ao "Embaralhado".

Um dos aplicativos analisados foi o objeto de aprendizagem apresentado por Finizola et al (2016) denominado Achei a palavra (AaP) e disponível no endereço http://aap.dcx.ufpb.br. Trata-se de uma ferramenta na forma de um jogo educativo web com a temática do jogo da forca, ou seja, o objetivo para se concluir os desafios propostos no jogo é acertar todas as letras que compõem a palavra relacionada à figura apresentada. Um de seus pontos fortes é que pode ser acessado por navegadores de diferentes tipos de dispositivo. Outro ponto positivo é a possibilidade de, como o "Embaralhado", possuir um módulo de gerenciamento de conteúdo, permitindo assim, criar novos contextos e desafios, excluí-los e editá-los. Esta funcionalidade é disponibilizada tanto para novos conteúdos quanto os que a aplicação já possui. Porém, o AaP na sua versão atual possui algumas características em seu projeto que o diferenciam do Embaralhado, como o fato de que ao customizar o conteúdo, o usuário afeta outros usuários do sistema. Outra característica diferente é o fato de por enquanto o aplicativo apresentar problemas de visualização em telas de tamanho reduzido.

Outro aplicativo relacionado foi o proposto por Oliveira (2017) denominado "ABC da Forca", e inspirado no AaP. É um aplicativo voltado para dispositivos móveis, que possuam como sistema operacional a plataforma Android e está disponível na

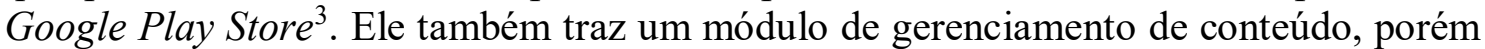
a edição e exclusão de conteúdo só é permitida para novos contextos e novos desafios. Uma característica diferente do Embaralhado encontrada na versão atual do jogo (Versão 1.0.4) é que quando acontece a inserção de novos desafios e contextos ao jogo,

\footnotetext{
${ }^{3}$ https://play.google.com/store/apps/details?id=tcc.ufpb.com.br.tcc
} 
existe uma forte dependência do jogo quanto às novas imagens do dispositivo que podem vir a ser utilizadas, uma vez que, se o usuário por algum motivo apagá-las, o aplicativo pode apresentar erros.

Um outro aplicativo selecionado para fazer parte desta análise é o software intitulado "Luz do Saber" (Rocha, 2016). Uma das qualidades encontradas no software é o fato dele ser multiplataforma, ou seja, existe a possibilidade de ser instalado em diferentes versões de sistemas operacionais, especificamente: Windows, Linux e Android, além de existir uma versão web. Vale ressaltar que a versão analisada neste trabalho foi a versão voltada para dispositivos móveis Android ${ }^{4}$. $\mathrm{O}$ aplicativo conta com um total de 16 atividades lúdicas, como bingo; memória; quebra-cabeça; etc. Uma funcionalidade encontrada é o fato de todas as atividades utilizarem o nome do educando, uma vez que, se constitui a palavra geradora por excelência no início do processo de alfabetização. Outro ponto positivo encontrado no aplicativo, é o fato de explorar áudios nas atividades. Contudo, o aplicativo não apresenta a possibilidade de alterar e gerenciar o conteúdo apresentado na aplicação, como o "Embaralhado", algo que pode ser bastante útil para pais ou professores que queiram explorar palavras específicas ligadas ao que o estudante está aprendendo na escola, conforme relatado por usuários do "Embaralhado".

\section{Resultados da Avaliação por Observação Direta}

Para realizar uma avaliação por observação direta do uso do OA "Embaralhado", foram selecionadas 44 crianças matriculadas no Instituto Agras de Ensino, situado na cidade de Mamanguape-PB. Estas, por sua vez, estavam divididas em 3 turmas onde: 14 crianças pertenciam ao jardim II na primeira turma, 11 crianças pertenciam também ao jardim II da segunda turma e a terceira turma consistia de um total de 19 crianças do $1^{\circ}$ ano. Foram observados os critérios de avaliação de Objetos de Aprendizagem seguindo os questionamentos pedagógicos das abordagens comportamentalistas, construtivistas e sócio-interacionistas propostas por Reategui e Finco (2010) e critérios técnicos também propostos pelos autores. Outro fator observado foi a forma como princípios de usabilidade estão sendo atendidos nesta versão do aplicativo (versão 1.0.2). Vale ressaltar que esta avaliação preliminar foi feita apenas pelos autores deste trabalho com base em observações feitas nestes alunos selecionados e em conversas com professores.

Foram propostos para os alunos das turmas selecionadas atividades constituídas de uma lista de associação de palavras e figuras. As palavras utilizadas nas atividades foram definidas pelas respectivas professoras de cada turma. O objetivo dos alunos era de escrever as palavras correspondentes às imagens apresentadas. Uma abordagem bastante próxima do que acontece no "Embaralhado" era solicitado nas atividades. Além disso, deveriam também colorir as imagens da atividade. Inicialmente cada turma foi dividida pela metade, formando dois grupos A e B. O grupo A ficaria com a responsabilidade de concluir esta tarefa em papel enquanto o grupo $\mathbf{B}$ estaria utilizando o OA no tablet com as mesmas palavras apresentadas na atividade. Quando ocorresse o término da atividade escrita, aconteceria uma troca de atividades, ou seja, os alunos que estavam utilizando o OA agora iriam realizar a atividade escrita e vice-versa.

Durante toda a atividade o comportamento dos alunos foi analisado, com o objetivo de se poder com base em observações responder ao questionário proposto na metodologia de avaliação adotada. Com base nisto, pôde-se perceber que o jogo em si tem características que o enquadram mais na abordagem Comportamentalista. Este resultado foi obtido considerando as respostas às questões do questionário de Reategui e

\footnotetext{
${ }^{4} \mathrm{https} / / /$ play.google.com/store/apps/details?id=br.gov.ce.seduc.luzdosaber\&hl=pt_BR
} 
Finco (2010) baseadas em Skinner (1982), tais como a forma do aplicativo testar o aluno após cada seção e o fato de oferecer recompensas para respostas corretas. Porém, vale enfatizar que dependendo da forma com que pode ser usado em sala de aula, este pode atender a critérios relacionados a outras abordagens pedagógicas. Por exemplo, observou-se que os alunos por vezes se comunicavam auxiliando uns aos outros, durante a resolução do desafio proposto no OA e quando tinham alguma dificuldade não sentiam receio de pedir ajuda. Também foi observado, que em alguns casos, existia a formação de duplas, onde dois alunos ficavam com um tablet e juntos jogavam e se ajudavam durante a partida, o que o aproxima dos critérios propostos por Reategui e Finco (2010) para OAs que seguem uma abordagem sócio-interacionista de Vygotsky, que determina que as interações sociais entre estudantes, e entre estudantes e professores, têm um papel fundamental nos processos de aprendizagem. Este aspecto da avaliação foi importante para que se possa observar que um mesmo aplicativo pode ser aplicado de diferentes formas pelo professor obtendo diferentes resultados do ponto de vista pedagógico.

Outro fator observado nesta avaliação por observação foi a comprovação da capacidade de adaptação do conteúdo da aplicação com relação ao público-alvo, uma vez que foi possível aplicar o OA em turmas distintas com relação aos níveis escolares (Jardim II e $1^{\circ}$ ano).

Já com relação aos aspectos técnicos, a fim de avaliar de acordo com as diretrizes encontradas no trabalho de Reategui e Finco (2010), vale ressaltar que o OA se manteve estável não apresentando qualquer erro durante a execução. Toda a interface do OA foi compreendida da maneira que foi projetada (Botões, imagens e links), o feedback aconteceu nos momentos esperados, como em casos de erros e acertos dos desafios, a navegação se mostrou fluida sem acontecerem travamentos que comprometessem a utilização. Pôde-se perceber também que não existiu confusão ou questionamentos sobre qual tela estava sendo mostrada, o estado do nível para a conclusão das partidas se manteve sempre visível, o controle de navegação e a prevenção de erros foi considerada aceitável, além da interface ter sido considerada minimalista e esteticamente agradável. Das 44 crianças selecionadas, um total de 40 disseram que gostaram de utilizar o jogo. Isso se comprovou com base no número de partidas jogadas que se manteve entre 2 e 3 partidas e considerando que cada uma das partidas levou em torno de 10 a 15 minutos para ser finalizada. Um comportamento observado durante a utilização do OA pelas crianças que reforça este nível de satisfação ao utilizá-lo foi o fato de cerca de 7 crianças entregarem a tarefa sem colori-la alegando que queriam jogar o "Embaralhado" novamente.

Durante a avaliação por observação direta se pôde identificar algumas limitações nas funcionalidades que se resolvidas poderiam trazer uma evolução ao "Embaralhado". Uma delas é o fato do aplicativo não possuir um banco de dados em rede, o que facilitaria o gerenciamento de conteúdo da aplicação em vários dispositivos simultaneamente. Outro fator observável foi a necessidade de se implementar no OA a possibilidade de se utilizar letras da forma cursiva (maiúsculas e minúsculas) e bastão (minúscula). Com relação a possíveis falhas, foi descoberto que o aplicativo permitia cadastrar uma pontuação sem o nome do jogador. O Quadro disponível online ${ }^{5}$ apresenta um detalhamento da análise considerando os aspectos pedagógicos e técnicos propostos por Reategui e Finco (2010) discutidos anteriormente.

\footnotetext{
${ }^{5}$ https://doi.org/10.5281/zenodo.1312255
} 


\section{Avaliação por Pais ou Responsáveis e Professores}

Além de uma avaliação dos aspectos pedagógicos e técnicos do jogo, tomando como base observações do comportamento de crianças inseridas no processo de alfabetização, foi feita uma avaliação usando formulários online respondidos por pais/responsáveis de crianças em processo de alfabetização e professores que lecionem em séries iniciais. Os formulários e suas respostas detalhadas podem ser encontradas também online ${ }^{6}$. Desta vez, o foco foi avaliar o nível de aceitação do aplicativo para o uso na alfabetização. A forma de coleta de dados seguiu a seguinte metodologia: foi feita uma divulgação dos formulários de avaliação e do aplicativo em grupos/páginas de alfabetização e letramento que reúnem diversos pais e professores na rede social do Facebook, disponíveis online ${ }^{7}$. Os formulários foram divulgados nos grupos de alfabetização durante o período de 14 de outubro a 2 de novembro de 2017. No total, foram obtidos 23 registros de respostas. Destes, 7 foram respostas ao formulário de avaliação por parte de professores ( 3 professores foram da escola onde foi feita a observação direta) e 16 foram respostas ao formulário de avaliação respondido por pais e responsáveis.

$\mathrm{Na}$ avaliação direcionada aos professores buscou-se identificar o nível de aceitabilidade de utilização do OA avaliado neste trabalho. Quando questionados sobre se utilizariam o aplicativo em sala de aula com seus alunos, todos afirmaram que "Sim", o que demostra um interesse no uso do aplicativo pelos profissionais da área. $\mathrm{O}$ mesmo ocorreu quando os professores foram questionados sobre a possibilidade de sugestão do "Embaralhado" a colegas de profissão, além da questão sobre a crença do OA apoiar o processo de alfabetização. Foi possível analisar que todos responderam que "Sim".

A avaliação direcionada aos pais e responsáveis teve o objetivo de verificar a utilização do aplicativo fora do contexto escolar. Como o "Embaralhado" está disponível na Google Play Store, existe a possibilidade do OA ser baixado e instalado em dispositivos móveis. Quando questionados sobre a possibilidade de utilização do OA outras vezes como material complementar para as crianças, todos responderam que "Sim", o que mais uma vez demonstra interesse de uso de aplicativos fora do ambiente escolar. Como ocorreu na avaliação voltada para os professores, os pais também foram questionados sobre a crença do "Embaralhado" apoiar o processo de alfabetização e sobre a possibilidade de indicação do aplicativo como material de apoio à alfabetização e todos responderam que "Sim" a ambas as questões.

Com respeito ao nível de dificuldade de se utilizar o aplicativo por parte das crianças e alunos, observou-se que é possível que melhorias precisem ser feitas. Considerando as respostas dadas, é possível perceber uma predominância de dificuldade média com relação à utilização do aplicativo. Cabe a futuras avaliações conseguir ter resultados mais precisos com relação a esta dificuldade de utilização do "Embaralhado" para identificar se a dificuldade foi com o aplicativo em si ou com as palavras.

Com relação à opinião por parte dos professores e pais/responsáveis a respeito do OA possuir uma base de dados personalizável, todos acharam esta proposta muito interessante e acreditam que este é um recurso diferencial, pois existe a possibilidade se

\footnotetext{
${ }^{6} \mathrm{https}: / /$ doi.org/10.5281/zenodo. 1312255

${ }^{7}$ https://www.facebook.com/groups/VANESSA.PEREIRA

https://www.facebook.com/groups/283979708729585

https://www.facebook.com/groups/escrita.alfabetiza

https://www.facebook.com/groups/pactocentraldeminas

https://www.facebook.com/Alfabetiza\%C3\%A7\%C3\%A3o-Criativa-1897583967120861

https://www.facebook.com/alemdaalfabetizacao

https://www.facebook.com/groups/pactoparaalfabetizacao
} 
poder criar novos contextos e desafios para serem utilizados de acordo com a necessidade das crianças ou alunos. Nas respostas dos pais, observa-se que 56,3\% acharam a proposta muito boa, já 18,8\% responderam que acharam interessante, mas difícil de se configurar. Por parte dos professores, um total de $85,7 \%$ considerou muito interessante o recurso, por permitir que possam interagir com seus alunos com maior frequência e utilizar o jogo de acordo com as suas atividades.

Os principais pontos positivos identificados no OA foram os seguintes: liberdade de fazer edições no conteúdo do jogo; oportunidade e motivação do desenvolvimento psicossocial do usuário (crianças e jovens/adultos inseridos no processo de alfabetização); motivação da comunicação entre a família e a criança; estimulação da coordenação motora; realização de uma atividade de aprendizado divertida; estimulação da criatividade e do raciocínio; possibilidade da descoberta de novos vocabulários; possiblidade de criar desafios de acordo com desempenho do usuário; uso de cores diferentes em cada letra diferenciando-as. De modo geral, foram levantados os seguintes aspectos negativos ou sugestões: mudança do termo "Contexto"; criação de um novo modo de jogo; recurso de edição mais visível ao usuário; tutorial explicativo sobre o modo de jogar; pontuação do usuário sempre visível.

\section{Conclusões e Trabalhos Futuros}

Este trabalho apresentou o OA "Embaralhado" e sua avaliação por observação direta de critérios pedagógicos e técnicos e também por questionários para verificar o nível de aceitabilidade por professores que atuam na área da alfabetização e pais/responsáveis que possuem crianças que estão nesta fase da educação.

A avaliação realizada com base nas diretrizes propostas por Reategui e Finco (2010) considerou que o "Embaralhado" contemplou pelas observações principalmente aspectos da abordagem pedagógica Comportamentalista, mas pode também incluir alguns aspectos da abordagem sócio-interacionista dependendo de como for utilizado. Foi também possível identificar aspectos técnicos positivos como: robustez, estabilidade, adaptabilidade de acordo com as necessidades de cada usuário e um uso adequado do emprego de imagens. O Processo de análise dos formulários demonstrou que o "Embaralhado" foi bem aceito por pais/responsáveis e professores e que pode apoiar o processo de alfabetização favorecendo a motivação.

No entanto, algumas melhorias/correções futuras podem ser feitas, como a inclusão de outros modelos de letras (bastão minúscula e cursiva) e a criação de um banco de dados em rede para facilitar o gerenciamento de conteúdo em diferentes dispositivos por diferentes usuários. Foi possível identificar que o termo "Contexto" pode ser revisto. Pensa-se também em uma integração com dicionários para evitar grafias incorretas cadastradas. Outros trabalhos futuros previstos são novas avaliações com ênfase na efetividade de aprendizagem, incluindo também adultos e jovens, além da exploração do OA no ensino de idiomas. É importante futuramente avaliar o quão efetivo o aplicativo pode ser na aprendizagem durante o processo de alfabetização.

\section{Agradecimentos}

Gostaríamos de agradecer às valiosas sugestões dadas pelas professoras Thaíse Costa e Flávia Vasconcelos durante a realização deste trabalho, além de todo o apoio das professoras Alice, Alessandra e Yara, do Instituto Agras, e dos usuários do "Embaralhado" que nos forneceram feedbacks importantes. 


\section{Referências}

BLANDINO, J. F. O uso de objetos de aprendizagem como recurso de apoio às dificuldades na alfabetização. UNESP, 2016. 91p. Dissertação de mestrado.

CAMPOS, Gilda Helena Bemardino de. Construção e validação de ficha de avaliação de produtos educacionais para microcomputadores. Rio de Janeiro, 1989.

DA SILVA NETTO, D. P.; DOS SANTOS, M. W. A. AlfaGame: Um Jogo para auxílio no processo de alfabetização. In: Anais do Simpósio Brasileiro de Informática na Educação-SBIE. 2012.

FINIZOLA, J. S.; DANTAS, A.; SANTANA, R.; NEVES, T. Achei a Palavra: Um objeto de aprendizagem colaborativo para apoiar a alfabetização. RENOTE, v.14, n.2, 2016.

GIL, A. C. Como elaborar projetos de pesquisa. São Paulo, Atlas, 2002.

MAFFEZZOLLI, E. C. F.; BOEHS, C. G. E. Uma reflexão sobre o estudo de caso como método de pesquisa. Revista da FAE, v. 11, n. 1, 2008.

NESBIT, J.; BELFER, K.; LEACOCK, T. Learning Object Review Instrument (LORI) User. Manual E-Learning Research and Assessment Network. 2010.

OLIVEIRA, D. Proposta de um aplicativo personalizável para auxiliar no processo de alfabetização baseado no jogo da forca. Trabalho de conclusão do curso de Licenciatura em Ciência da Computação. Rio Tinto, 2017.

PÉRSIO, N. S.; BERTOSO, E. B. F. Dificuldades de Aprendizagem no Processo de Alfabetização. Disponível em: <http://www.profala.com/arteducesp180.html>. Acesso em 3 ago. 2017.

REATEGUI, E.; FINCO, M. D. Proposta de diretrizes para avaliação de objetos de aprendizagem considerando aspectos pedagógicos e técnicos. RENOTE, v.8, n.3, 2010.

ROCHA, J. S. R. Alfabetização mediada por computador: uma experiência com o software Luz do Saber. UEFS, 2016. 431 p. leDissertação de mestrado.

SKINNER, B. F. Sobre o behaviorismo. São Paulo: Cultrix/Edusp. 1982.

SILVA, C. R. O. Bases pedagógicas e ergonômicas para concepção e avaliação de produtos educacionais informatizados. Florianópolis: UFSC, 1998. 122p. Dissertação de Mestrado.

SOUZA, K.; CORRÊA, A. G. D. AugaBeti: um software educacional para apoio ao processo de alfabetização de crianças com deficiência visual. Anais do Computer on the Beach, p. 51-60, 2012.

TAROUCO, L. Avaliação de objetos de aprendizagem. Disponível em: $<$ http://penta2.ufrgs.br/edu/avaliacao/avalObjetosAprendizagem.pdf $>$. Acesso em: 29 ago. 2017. 